\title{
CONSTRUÇÃO E VALIDAÇÃO DE CONTEÚDO DE QUESTIONÁRIO PARA IDENTIFICAÇÃO DE CRENÇAS SOBRE O ENSINO DA TEMÁTICA ALIMENTAÇÃO SAUDÁVEL NO AMBIENTE ESCOLAR
}

\author{
Ana Luiza Sander Scarparo ${ }^{1}$, Tania Beatriz Iwaszko Marques² ${ }^{2}$ Jose Cláudio Del Pino $^{3}$
}

Resumo: Este trabalho teve como objetivo descrever o processo de construção e validação de um questionário destinado à identificação de crenças sobre o ensino da temática alimentação saudável no ambiente escolar. O questionário foi elaborado utilizando uma escala do tipo Likert, para constatar o grau de concordância do participante com cada afirmativa proposta. As afirmativas foram estruturadas com base na literatura das áreas de nutrição e de educação e foram avaliadas por especialistas, que analisaram conteúdo, formulação e pertinência. A versão final do questionário foi composta por 54 afirmativas, que foram agrupadas em eixos, de acordo com o conteúdo. O questionário consiste em um instrumento para identificação das crenças relacionadas ao ensino da temática alimentação saudável, que pode ser aplicado em diferentes atores envolvidos com a alimentação escolar, permitindo, entre outras possibilidades, constatar a visão tanto de profissionais como de acadêmicos da área de educação e nutrição sobre o assunto.

Palavras-chave: Questionário. Crenças. Ensino. Alimentação saudável. Ambiente escolar.

\section{CONSTRUCTION AND VALIDATION OF THE CONTENTS FOR A QUESTIONNAIRE ON BELIEFS ABOUT THE TEACHING OF THE HEALTHY EATING ISSUE IN THE SCHOOL ENVIRONMENT}

Abstract: The purpose of this paper was to describe the construction and validation process of a questionnaire aimed at identifying beliefs about the teaching of the healthy eating issue in the school environment. The questionnaire was elaborated with the use of a Likert type scale to ascertain the degree of participant concordance with every statement proposed. The statements were structured based on the nutrition and education areas literature and were assessed by specialists, who analyzed the contents,

1 Nutricionista. Doutora em Educação em Ciências: Química da Vida e Saúde - Universidade Federal do Rio Grande do Sul (UFRGS). Contato: anascarparo@gmail.com.

2 Psicóloga. Doutora em Educação. Professora de Psicologia da Educação na Faculdade de Educação da UFRGS. Contato: taniabimarques@bol.com.br.

3 Químico. Doutor em Engenharia de Biomassa. Professor do Programa de Pós-Graduação Educação em Ciências: Química da Vida e Saúde - UFRGS. Contato: delpinojc@yahoo.com.br. 
formulation and pertinence. The final version of the questionnaire comprised 54 statements grouped into axes according to the contents. The questionnaire consists in an instrument to identify beliefs related to the teaching of the healthy eating issue that may be applied to different players involved with school feeding and allows to, among other possibilities, ascertain the view of both professionals and scholars from the education and nutrition area on the subject.

Keywords: Questionnaire. Beliefs. Teaching. Healthy eating. School environment.

\section{Introdução}

De acordo com a Legislação vigente, alimentação escolar é entendida como toda a alimentação realizada ou todo alimento oferecido, independente de sua origem, durante o período que o estudante estiver no ambiente escolar (CFN, 2005; 2010; BRASIL, 2009). Por isso, a alimentação na escola é considerada como uma forma de garantir aos escolares o direito de uma alimentação de qualidade, que atenda as suas necessidades nutricionais, e, também, como um momento pedagógico (BOOG, 2008; BRASIL, 2006; 2009; BARBOSA et al., 2013).

A alimentação não se reduz à questão puramente nutricional, mas é um ato social, inserido em um contexto cultural, e, portanto, a alimentação escolar pode e deve ter função pedagógica, devendo estar inserida no contexto curricular (BRASIL, 2006). Sendo assim, a alimentação servida aos escolares está inserida em um processo, contínuo e permanente, de Educação Alimentar e Nutricional (EAN), que é composto por um conjunto de estratégias e ações que têm como propósito incentivar a cultura e a valorização da alimentação, considerando a autonomia nas escolhas alimentares e a necessidade de respeitar, assim como de refletir e/ou modificar "crenças, valores, atitudes, representações, práticas e relaçôes sociais que se estabelecem em torno de uma alimentação quantitativa e qualitativamente adequada", a fim de contemplar tanto a saúde, o prazer, o convívio social, como a sustentabilidade ambiental (BOOG, 2008, p.26).

Boog (2008) alerta que, ao considerar que a alimentação escolar está relacionada a todos os atos ligados ao comer dentro do ambiente escolar, deve-se atentar para a qualidade dos alimentos que são oferecidos às crianças. Uma vez que é possível controlar o consumo de alimentos e prover opções de boa qualidade, a escola torna-se um local propício para promover mudanças socioambientais e, principalmente, favorecer escolhas alimentares saudáveis. De acordo com a autora, há um consenso sobre a competência da escola de ensinar quais são os alimentos que compõem uma alimentação saudável, bem como ensinar a criança a ter bons hábitos alimentares.

A Portaria Interministerial 1.010/2006, que institui diretrizes para a promoção da alimentação saudável na educação básica, das escolas da rede pública e privada, com a proposta de favorecer o desenvolvimento de ações que promovam e garantam a adoção de práticas alimentares mais saudáveis no ambiente escolar, também apresenta uma preocupação com a qualidade dos alimentos ofertados aos estudantes. A Portaria reforça que os locais de produção e fornecimento de alimentos (refeitórios, restaurantes, 
bares, cantinas e lanchonetes), na escola, devem redimensionar as ações desenvolvidas no cotidiano escolar, valorizando a alimentação como estratégia de promoção da saúde. Entre os eixos referidos nesta legislação, para efetivar a promoção da alimentação saudável, encontram-se: a restrição ao comércio e à promoção comercial no ambiente escolar de alimentos e preparações com altos teores de gordura saturada, gordura trans, açúcar livre e sal e incentivo ao consumo de frutas, legumes e verduras; e o estímulo à produção de hortas escolares para a realização de atividades com os alunos e a utilização dos alimentos produzidos na alimentação ofertada na escola (BRASIL, 2006).

A promoção e o emprego de uma alimentação saudável e adequada é uma das diretrizes que norteiam a execução do Programa Nacional de Alimentação Escolar (PNAE), assim como o direito à alimentação escolar, a fim de garantir a Segurança Alimentar e Nutricional dos estudantes, e o incentivo à aquisição de produtos da agricultura familiar, principalmente alimentos orgânicos e agroecológicos. Por meio da oferta de uma alimentação que atenda as necessidades nutricionais dos estudantes e do desenvolvimento de ações de EAN, o PNAE tem como propósito contribuir no crescimento e desenvolvimento biopsicossocial, na aprendizagem, no rendimento escolar e na formação de hábitos alimentares saudáveis dos escolares matriculados, na educação básica, em escolas públicas brasileiras (BRASIL, 2009; 2013). Cabe destacar que estas diretrizes e objetivos que norteiam a alimentação escolar pública podem ser generalizados para a alimentação escolar em escolas privadas (SCARPARO, 2017).

No contexto da realização de ações de educação em alimentação e nutrição, no ambiente escolar, entre os objetivos propostos encontram-se: a promoção da alimentação saudável - acreditando-se que as ações realizadas, com o propósito de favorecer melhores práticas alimentares, podem ampliar e fomentar a capacidade de decisão dos indivíduos com relação ao seu comportamento alimentar; e a alfabetização em nutrição - considerando que a finalidade das ações não se limita à mudança de comportamento, entende-se que a divulgação de informações irá possibilitar que o indivíduo tome decisões que favoreçam a adoção de um estilo de vida saudável, assumindo o cuidado com a sua alimentação (BRASIL, 2008).

Para que o processo de EAN no ambiente escolar seja efetivo e atinja os objetivos propostos, alguns aspectos devem ser levados em consideração, para que efetivamente o tema alimentação seja inserido no cotidiano da escola e, inclusive, nas práticas pedagógicas (BARBOSA et al., 2013). Todas as áreas do conhecimento contribuem para discutir os diferentes assuntos, aspectos e dimensões que estão relacionadas com a alimentação e a nutrição humana, sinalizando a necessidade de atividades transdisciplinares. A EAN, ao compor o currículo escolar, pode ser trabalhada de maneira agregada aos saberes consagrados nos conteúdos escolares, e, portanto, não deve ser centrada nas relações entre os alimentos e os seus nutrientes e os benefícios para a saúde. Sendo assim, o ensino da temática não deve ficar restrito às áreas de ciências ou educação física, uma vez que a alimentação possibilita a relação com diversos conteúdos e áreas de conhecimento. Ao mesmo tempo, as práticas de EAN não devem ser restritas à sala de aula ou a ações pontuais ou fragmentadas, sendo pertinente 
o planejamento e o desenvolvimento de um conjunto de estratégias. E, para isso se efetivar, os diferentes atores da comunidade escolar devem estar educados do ponto de vista da alimentação, assim como devem apoiar e incentivar a EAN, já que esta é uma ação que envolve e demanda de um aporte teórico e técnico das diferentes áreas e profissionais (BARBOSA et al., 2013; BOOG, 2008; SCARPARO, 2017).

Entre as ações a serem implementadas para a promoção da alimentação saudável no ambiente escolar, a Portaria 1.010/2006 refere: definir estratégias, em conjunto com a comunidade escolar, para favorecer escolhas saudáveis; sensibilizar e capacitar os profissionais envolvidos com alimentação na escola para produzir e oferecer alimentos mais saudáveis; desenvolver estratégias de informação às famílias, enfatizando sua coresponsabilidade e a importância de sua participação neste processo; restringir a oferta e a venda de alimentos com alto teor de gordura, gordura saturada, gordura trans, açúcar livre e sal e desenvolver opções de alimentos e refeições saudáveis na escola; aumentar a oferta e promover o consumo de frutas, legumes e verduras; estimular e auxiliar os serviços de alimentação da escola na divulgação de opções saudáveis e no desenvolvimento de estratégias que possibilitem essas escolhas (BRASIL, 2006).

Diante desta demanda, o desenvolvimento de projetos de educação alimentar e nutricional, no contexto escolar, exige uma colaboração mútua entre professores e nutricionistas. Propõe-se que os dois profissionais sejam parceiros, uma vez que os professores são considerados os mais indicados para trabalhar esse assunto com crianças, pois já mantêm um forte vínculo com os estudantes e têm o conhecimento pedagógico, e os nutricionistas têm o conhecimento técnico da nutrição, estando preparados para apoiar e desenvolver programas e ações de EAN (BOOG, 2008; SCARPARO, 2017).

Ruwer e Mainbourg (2015), no trabalho realizado para verificar as práticas alimentares e pedagógicas em quatro escolas particulares de Manaus, constataram, ao entrevistar coordenadores pedagógicos e professores, que a Portaria 1.010/2006, que institui as diretrizes para a promoção da alimentação saudável, era desconhecida por esses profissionais. Além disso, nas falas dos participantes, observaram a necessidade de capacitação para os professores, pois eles não se sentem aptos para ensinar bons hábitos alimentares ou preparados e habilitados para trabalhar a alimentação saudável com os estudantes.

Soares e Bejarano (2008), ao proporem uma reflexão sobre crenças e a sua influência no trabalho do educador, referem que as crenças são elaborações individuais, produzidas a partir do contexto sociocultural, das relações estabelecidas e vivenciadas no meio social, familiar, educacional e profissional. Diferentemente do conhecimento científico, não necessitam de comprovações para serem aceitas, são pressupostos que o sujeito constrói como sendo verdade, muitas vezes elaboradas sem uma reflexão. Para eles, o mesmo aconteceria com alguns saberes dos professores, que estariam cristalizados e conseguiriam interferir em suas atitudes, agindo como um filtro para a assimilação de conhecimentos científicos. 
Custódio, Clement e Ferreira (2012), bem como Paiva e Prett (2009), verificaram que as crenças dos professores orientam as práticas educacionais, em sala de aula, e influenciam na aprendizagem dos alunos. As crenças dos professores têm um importante papel na organização do conhecimento e informação, orientando a escolha do momento, do tipo e do objetivo que se tem ao propor atividades didáticas. Os resultados do trabalho de Bejarano e Carvalho (2003) sinalizam que, quando o estudante ingressa no curso de licenciatura, ele traz consigo as imagens vividas do trabalho do professor durante a educação básica, tanto imagens positivas como negativas do ser professor e seu papel. Neste sentido, consideram que compreender as crenças dos professores ou dos futuros professores é uma promissora rota de pesquisa na medida em que crenças influenciam percepções e julgamentos das pessoas.

Scoaris, Pereira e Santin Filho (2009) acreditam que, somente após a identificação e a avaliação das crenças e atitudes dos professores com relação ao tema em estudo, é possível pensar ações efetivas que busquem a valorização de abordagens sociais como estratégia para melhorar os processos de ensino e de aprendizagem.

Sendo assim, justifica-se a criação de uma ferramenta para investigar as crenças sobre o ensino da temática alimentação saudável, uma vez que há uma demanda para a promoção da alimentação saudável no ambiente escolar, sendo a escola considerada um local propício para o desenvolvimento de ações de EAN, principalmente, em função do aumento crescente dos índices de sobrepeso e obesidade em crianças e adolescentes e por ser na infância que se inicia a formação dos hábitos alimentares.

Este trabalho tem como objetivo descrever o processo de construção e validação de um questionário destinado à identificação de crenças sobre o ensino da temática alimentação saudável no ambiente escolar. A pesquisa recebeu financiamento da Capes e, além de seguir as orientações da Resolução CNS no 466/2012 que regulamenta ética e pesquisa no Brasil, foi submetida à apreciação da Comissão de Pesquisa do Instituto de Ciências Básicas da Saúde (COMPESQ/ICBS), que emitiu parecer favorável à sua realização.

\section{Metodologia de elaboração do questionário}

Para investigar as crenças sobre o ensino da temática alimentação saudável no ambiente escolar, optou-se por elaborar um questionário que possibilitasse verificar o grau de concordância dos respondentes com cada afirmação proposta, utilizando, para tanto, uma escala do tipo Likert (1932).

De acordo com Silva Junior e Costa (2014, p.4), a escolha da escala, a ser utilizada em um questionário, é uma decisão que deve levar em consideração o interesse e o tipo de pesquisa, assim como as características e as peculiaridades do público alvo (respondentes). Ainda, os autores referem que no campo das "ciências sociais e comportamentais, a mensuração de variáveis de interesse é realizada por meio de 
escalas específicas, as quais são construídas de modo a se adaptarem à natureza abstrata de grande parte dos construtos".

No contexto das ciências comportamentais, a escala do tipo Likert é bastante utilizada para mensurar atitudes. Os pesquisadores, que utilizam instrumentos com essa escala, desenvolvem um conjunto de afirmações relacionadas a um determinado constructo e cabe aos respondentes manifestar seu grau de concordância com cada assertiva proposta, em uma escala do tipo: (1) discordo inteiramente/totalmente; (2) discordo ou discordo parcialmente; (3) nem concordo nem discordo; (4) concordo ou concordo parcialmente; (5) concordo inteiramente/totalmente (SILVA JUNIOR; COSTA, 2014; SCOARIS; PEREIRA; SANTIN FILHO, 2009).

Entre as vantagens ao optar pelo uso dessa escala, observa-se que ela é de fácil elaboração e aplicação, é objetiva, é homogênea e, ainda, aumenta a probabilidade de mensuração de atitudes unitárias (SCOARIS; PEREIRA; SANTIN FILHO, 2009). Para Silva Junior e Costa $(2014$, p.5), uma grande vantagem da escala Likert "é sua facilidade de manuseio, pois é fácil a um pesquisado emitir um grau de concordância sobre uma afirmação qualquer".

Em contrapartida, uma dificuldade mencionada no uso da escala Likert é a exigência ou necessidade do respondente ter que "verificar o conteúdo da proposição do item e, em seguida, opinar discordando ou concordando com a afirmação, considerando ainda a intensidade desta concordância". Com relação a isso, o uso dos advérbios, como totalmente e parcialmente, poderia dificultar o posicionamento do respondente e, para alguns deles, pode não ficar muito clara a distinção entre as opções de resposta de concordância parcial e discordância parcial (SILVA JUNIOR; COSTA, 2014, p.5). Além disso, em função da escala quantificar e padronizar respostas, constata-se a impossibilidade de "deteç̧ão de nuances e sutilezas de atitudes, que por sua vez são percebidas nas entrevistas e questionários abertos" (SCOARIS; PEREIRA; SANTIN FILHO, 2009, p.908).

Mesmo com essas possíveis dificuldades ou desvantagens, a Escala de Likert é uma das escalas mais utilizadas em pesquisas de opinião e considerada como uma das mais adequadas para instrumentos longos, apresentando grande facilidade de adaptação para um número maior de temas (SILVA JUNIOR; COSTA, 2014).

A construção do instrumento consiste em um processo que se inicia pela elaboração dos itens até os testes de validade e de precisão. Os itens, usualmente, são elaborados na forma de afirmações e devem abranger diferentes aspectos ou dimensões do fenômeno a ser investigado ou avaliado, devendo expressar o comportamento das pessoas frente ao objeto de interesse (SCOARIS; PEREIRA; SANTIN FILHO, 2009).

Para a elaboração das afirmações, relacionadas ao ensino da temática alimentação saudável no ambiente escolar, foi consultada tanto a literatura da área de nutrição como da educação relacionada ao assunto. Inicialmente, foram elaboradas 45 afirmações, de forma a abranger os diferentes aspectos que a literatura e o cotidiano vêm evidenciando 
sobre o papel da escola, dos professores, dos escolares e de sua relação com a alimentação, a alimentação escolar, os hábitos alimentares, e os responsáveis pelo ensino da temática.

Em função de não haver consenso para muitos aspectos e, principalmente, para verificar se as 45 afirmações do questionário contemplavam as variáveis relacionadas ao ensino da temática, assim como se havia clareza na formulação de cada assertiva, optou-se por realizar uma validação de conteúdo do instrumento elaborado.

\section{Validação de conteúdo das afirmações do questionário}

Monteiro e Hora (2014, p. 39) referem que "qualquer dispositivo de medição é válido se ele faz aquilo que se propóe a fazer", sendo que a validade do instrumento estará relacionada com a sua finalidade específica, bem como com o contexto sociocultural e linguístico no qual será utilizado ou aplicado. A validação de uma escala é uma das etapas que dá credibilidade ao instrumento. Portanto, a validade verifica se o instrumento tem a capacidade de medir com precisão o fenômeno a que se propõe, se consegue avaliar realmente o seu objetivo de estudo. Ou seja, os itens selecionados ou as afirmações formuladas para medir uma construção teórica representam todo o universo de questões que poderiam ser elaboradas sobre o conceito/conteúdo a ser medido (ALEXANDRE; COLUCI, 2011; SCOARIS; PEREIRA; SANTIN FILHO, 2009).

Entre as possibilidades de validação, a validação de conteúdo, embora apresente um caráter subjetivo, é uma estratégia importante no processo de desenvolvimento ou adaptação de instrumento de medidas, pois consiste em verificar a capacidade dos itens (selecionados para compor o instrumento) de representarem adequadamente o constructo em foco. $\mathrm{Na}$ validação de conteúdo é realizado um julgamento por especialistas, os juízes, que averiguam se a escala mede uma amostra representativa de todas as crenças, sentimentos e tendências de ação referentes ao fenômeno (MONTEIRO; HORA, 2014; ALEXANDRE; COLUCI, 2011; SCOARIS; PEREIRA; SANTIN FILHO, 2009).

Para tanto, são selecionados especialistas, qualificados na área de estudo, que analisam, mediante um roteiro estruturado, se os itens do instrumento contemplam o universo do conteúdo de interesse do investigador, bem como se o instrumento realmente é capaz de medir o que propõe (MONTEIRO; HORA, 2014). Os especialistas convidados têm como atribuição ou tarefa analisar os itens e verificar se são abrangentes e representam o conteúdo a ser medido, assim como avaliar a qualidade dos itens quanto à clareza e se seu conteúdo é compreensível e pertinente para a pesquisa. Recomenda-se que essa avaliação seja realizada por, no mínimo, seis especialistas (SCOARIS; PEREIRA; SANTIN FILHO, 2009).

Sendo assim, a fim de avaliar as afirmativas elaboradas para compor o questionário, optou-se por convidar especialistas (experts), tanto da área de nutrição como de educação, para examinarem a estrutura de cada afirmação, verificando se havia 
adequação do conteúdo e clareza na formulação da questão com relação ao objetivo do trabalho, bem como a pertinência da afirmação para avaliar as crenças sobre o ensino da temática alimentação saudável no ambiente escolar. Juntamente com o convite para os experts selecionados, foi enviado um "formulário de avaliação" elaborado para facilitar e padronizar a análise do conteúdo das afirmações. Neste formulário, os especialistas poderiam informar, para cada afirmação, se o conteúdo ou se a formulação gerou alguma "dúvida (?)" ou, ainda, sugerir melhorias, utilizando para isso o espaço "sugestão", conforme exemplificado na Figura 01.

Figura 01. Modelo do formulário enviado aos especialistas, contendo as informações solicitadas na avaliação

\begin{tabular}{|c|c|c|c|c|c|c|c|c|c|c|}
\hline & \multirow[t]{2}{*}{ AFIRMAÇÓES } & \multicolumn{3}{|c|}{$\begin{array}{l}\text { Adequaçäo do } \\
\text { conteúdo }\end{array}$} & \multicolumn{3}{|c|}{$\begin{array}{l}\text { Clareza na } \\
\text { formulaçăo }\end{array}$} & \multicolumn{3}{|c|}{ Pertinência } \\
\hline & & Sim & Näo & $?$ & Sim & Nāo & $?$ & manter & modificar & excluir \\
\hline 1 & Afırmaçäo & & & & & & & & & \\
\hline \multicolumn{11}{|c|}{ Sugestão: } \\
\hline \multicolumn{11}{|c|}{ Dúvida (?): } \\
\hline
\end{tabular}

Há uma grande variedade de critérios utilizados na seleção de experts para validação de instrumentos e procedimentos, porém a adoção de critérios inadequados na seleção dos especialistas poderá ter consequências na fidedignidade dos dados encontrados. Por isso, para aumentar a confiabilidade dos resultados, o especialista não deve ser selecionado somente por um critério, sendo pertinente que, além de critérios acadêmicos, também seja levada em conta a experiência, o conhecimento, as habilidades e a prática de cada candidato em relação ao que se deseja validar (GALDEANO; ROSSI, 2006; MELO et al., 2011).

Melo et al. (2011) verificaram, em seu estudo que teve como objetivo identificar os critérios utilizados para seleção de experts em pesquisas sobre validação de diagnósticos, intervenções ou resultados na área de enfermagem, que os trabalhos analisados apresentaram tendência a valorizar os especialistas que têm conhecimento prático em detrimento dos critérios estabelecidos por Fehring que prioriza a formação acadêmica. Essa preocupação de selecionar experts com tempo de experiência pode ser explicada pelo domínio dos selecionados sobre o tema, o que asseguraria uma maior acurácia da avaliação. Os autores, assim como Galdeano e Rossi (2006), consideram como sendo fundamental que o pesquisador descreva os critérios definidos de forma clara e detalhada, possibilitando a sua utilização por outros pesquisadores.

Sendo assim, para a seleção dos especialistas, que avaliaram as afirmações do questionário sobre o ensino da temática alimentação saudável no ambiente escolar, primeiramente, foram identificados e listados autores de publicações relacionadas à temática da pesquisa, entre elas livros, artigos científicos, dissertações e teses. Após a análise dos Currículos Lattes, foram selecionados seis especialistas da área de nutrição 
e sete da área de educação que se enquadravam em pelo menos três dos critérios de seleção referidos no Quadro 01.

Com relação às áreas relacionadas à temática da pesquisa, foram consideradas: nutrição; educação; alimentação escolar; alimentação saudável; nutrição da criança e do adolescente; educação alimentar e nutricional; educação e saúde; saúde pública; ensino/ docência; currículo; e formação de professores.

Quadro 01. Relação de critérios para seleção de especialistas da área de Nutrição e Educação

\section{Critérios de seleção:}

- ter graduação em nutrição;

- ter graduação em curso de licenciatura;

- ser mestre ou doutor em nutrição ou área afim (relacionada à temática da pesquisa);

- ser mestre ou doutor na área de educação ou educação em ciências ou ensino;

- possuir ou produção científica (artigo ou livro) ou experiência (acadêmica ou profissional) ou participação em projeto de pesquisa ou extensão que apresente relação à temática da pesquisa; - ser professor universitário, com projeto de pesquisa ou extensão relacionado à temática da pesquisa;

- ter produção científica (artigo ou livro) ou experiência (acadêmica ou profissional) com o assunto da pesquisa;

- ter participação em projeto de pesquisa ou extensão relacionado à temática da pesquisa.

Finalizada a seleção, para cada especialista selecionado, foi enviada uma mensagem com o convite e as orientações para participação, solicitando retorno da avaliação em 30 dias. Uma segunda mensagem, reforçando o convite e solicitando confirmação de recebimento, foi encaminhada dez dias antes do prazo final. Do total de especialistas convidados, sete encaminharam o formulário preenchido, sendo quatro da área de nutrição e três da educação. Não foi recebida nenhuma mensagem informando a impossibilidade de participar da avaliação.

Após o retorno dos especialistas, as considerações e sugestões foram compiladas, analisadas e foram realizadas as alterações necessárias e pertinentes. Foram incluídas 14 novas afirmativas; 23 foram modificadas, sendo que 18 sofreram pequenas alterações em palavras e cinco tiveram que ser reescritas; uma afirmativa foi subdividida em duas; cinco foram excluídas; e 15 foram mantidas sem alteração. Sendo assim, a versão final do questionário é composta por 54 afirmativas. Além disso, conforme sugerido, a ordem, de algumas afirmativas no questionário, sofreu alteração, e, em função da pertinência de algumas afirmativas para o trabalho, elas foram posicionadas entre as primeiras, assim como outras alternativas foram distanciadas. 


\section{Estudo piloto}

Para avaliar a formatação do questionário, o tempo médio de aplicação (preenchimento) e a clareza das instruções (orientações) de preenchimento, foi realizado um estudo piloto com acadêmicos de duas disciplinas dos cursos de pedagogia e nutrição, ambos da UFRGS. Após autorização dos professores responsáveis, o questionário foi entregue impresso. Foi informado aos estudantes o objetivo da pesquisa, orientada a forma de preenchimento do questionário e solicitado o consentimento da utilização dos dados para fins de divulgação. Foi entregue uma cópia impressa do questionário para cada acadêmico e o preenchimento ocorreu na sala de aula. $\mathrm{O}$ tempo médio de preenchimento foi de dez a quinze minutos.

Após a validação de conteúdo, utilizando a versão final do documento com 54 afirmativas, foi realizado um novo estudo piloto com a mesma finalidade do primeiro, com acadêmicos de nutrição e alunos de pós-graduação que cursavam uma disciplina do Programa de Pós-Graduação em Educação (PPGEDU/UFRGS). O questionário foi entregue impresso e o preenchimento ocorreu na sala de aula, após autorização do professor regente. O tempo médio de preenchimento se manteve entre dez e quinze minutos. Cabe referir que, por sugestão de um participante, foi feita a diferenciação do fundo das alternativas pares da nova versão impressa do questionário, com fundo cinza, a fim de facilitar o preenchimento do grau de concordância e evitar que questões fossem assinaladas equivocadamente ou esquecidas.

\section{Instrumento}

O questionário (QUADRO 2) elaborado para identificar as crenças sobre o ensino da temática alimentação saudável no ambiente escolar é composto por 54 afirmativas, que abrangem diferentes aspectos referentes ao tema de estudo. Para constatar o grau de concordância do participante com cada afirmativa proposta, optou-se por utilizar uma escala do tipo Likert, na qual o participante terá as seguintes opções de resposta: Concordo Totalmente (CT); Concordo Parcialmente (CP); Nem Concordo Nem Discordo (NCND); Discordo Parcialmente (DP); e Discordo Totalmente (DT).

Quadro 02. Questionário, contendo 54 afirmações e a escala do tipo Likert, elaborado para investigar as crenças sobre o ensino da temática alimentação saudável no ambiente escolar

\begin{tabular}{|c|c|c|c|c|c|c|}
\hline \multicolumn{7}{|c|}{ Questionário para investigar as crenças sobre o ensino da temática alimentação saudável no ambiente escolar } \\
\hline $\mathrm{N}$ & Afirmações & CT & $\mathrm{CP}$ & NCND & DP & DT \\
\hline 01 & $\begin{array}{l}\text { A escola é um local adequado para auxiliar a criança a desenvolver hábitos } \\
\text { alimentares saudáveis }\end{array}$ & & & & & \\
\hline 02 & $\begin{array}{l}\text { A escola é um local adequado para a criança aprender sobre alimentação } \\
\text { saudável. }\end{array}$ & & & & & \\
\hline 03 & $\begin{array}{l}\text { Ensinar aos escolares quais são os alimentos que compõem uma } \\
\text { alimentação saudável é uma das funções da escola. }\end{array}$ & & & & & \\
\hline
\end{tabular}




\begin{tabular}{|c|c|c|c|c|c|c|}
\hline \multicolumn{7}{|c|}{ Questionário para investigar as crenças sobre o ensino da temática alimentação saudável no ambiente escolar } \\
\hline $\mathrm{N}$ & Afirmações & $\mathrm{CT}$ & $\mathrm{CP}$ & NCND & $\mathrm{DP}$ & DT \\
\hline 04 & A alimentação na escola tem uma função pedagógica. & & & & & \\
\hline 05 & $\begin{array}{l}\text { A alimentação escolar gratuita é direito de todos os estudantes da } \\
\text { Educação Básica, de escolas públicas. }\end{array}$ & & & & & \\
\hline 06 & Deveria ser proibida a existência de bares e cantinas nas escolas. & & & & & \\
\hline 07 & $\begin{array}{l}\text { A existência de bares e cantinas nas escolas deveria ser condicionada à } \\
\text { venda exclusiva de alimentos saudáveis. }\end{array}$ & & & & & \\
\hline 08 & $\begin{array}{l}\text { Os escolares não comprariam alimentos e bebidas nos bares e cantinas se } \\
\text { esses comercializassem apenas produtos saudáveis. }\end{array}$ & & & & & \\
\hline 09 & $\begin{array}{l}\text { Os escolares têm interesse em atividades que envolvem a temática } \\
\text { alimentação saudável. }\end{array}$ & & & & & \\
\hline 10 & Os escolares não reconhecem a importância de ter uma boa alimentação. & & & & & \\
\hline 11 & Os escolares têm uma alimentação adequada em casa. & & & & & \\
\hline 12 & Os escolares têm uma alimentação adequada na escola. & & & & & \\
\hline 13 & Os escolares não gostam de consumir alimentos saudáveis. & & & & & \\
\hline 14 & $\begin{array}{l}\text { É papel dos pais e não dos professores ensinar as crianças a terem uma } \\
\text { boa alimentação. }\end{array}$ & & & & & \\
\hline 15 & $\begin{array}{l}\text { Informações sobre alimentação saudável influenciam nas escolhas } \\
\text { alimentares. }\end{array}$ & & & & & \\
\hline 16 & $\begin{array}{l}\text { Muitos profissionais da área da educação consideram importante a } \\
\text { temática alimentação, entretanto não trabalham por causa da falta de } \\
\text { tempo, pela sobrecarga de trabalho, pela falta de conhecimento especifico } \\
\text { do conteúdo e/ou por não conseguir articular o tema com os conteúdos de } \\
\text { suas disciplinas. }\end{array}$ & & & & & \\
\hline 17 & $\begin{array}{l}\text { Trabalhar o tema alimentação saudável, no ambiente escolar, não irá } \\
\text { modificar os hábitos alimentares dos escolares. }\end{array}$ & & & & & \\
\hline 18 & $\begin{array}{l}\text { Em função dos conteúdos curriculares, o tema alimentação saudável deve } \\
\text { ser trabalhado, preferencialmente, nas disciplinas de Ciências Biológicas e } \\
\text { de Educação Física. }\end{array}$ & & & & & \\
\hline 19 & $\begin{array}{l}\text { O tema alimentação saudável deve ser trabalhado de forma transdisciplinar } \\
\text { nas disciplinas que compõem o currículo. }\end{array}$ & & & & & \\
\hline 20 & $\begin{array}{l}\text { A alimentação saudável é um tema transversal e interdisciplinar, pois } \\
\text { nenhuma área do conhecimento isoladamente tem condiçôes suficientes } \\
\text { para explicá-la. }\end{array}$ & & & & & \\
\hline 21 & $\begin{array}{l}\text { O tema alimentação saudável constitui uma possibilidade para efetivar } \\
\text { a articulação e integração das áreas do conhecimento na organização do } \\
\text { currículo escolar. }\end{array}$ & & & & & \\
\hline 22 & $\begin{array}{l}\text { Em função do excesso de conteúdos programados para serem abordados } \\
\text { durante o ano letivo, não é possível trabalhar a temática alimentação } \\
\text { saudável como tema transversal. }\end{array}$ & & & & & \\
\hline 23 & $\begin{array}{l}\text { A temática alimentação saudável deve ser trabalhada na escola, } \\
\text { preferencialmente, pelo Nutricionista. }\end{array}$ & & & & & \\
\hline 24 & $\begin{array}{l}\text { Deve existir uma disciplina específica para trabalhar a temática alimentação } \\
\text { saudável com os escolares. }\end{array}$ & & & & & \\
\hline 25 & $\begin{array}{l}\text { Para os escolares aprenderem sobre alimentação saudável, não é suficiente } \\
\text { trabalhar a temática de forma transversal e interdisciplinar. }\end{array}$ & & & & & \\
\hline 26 & $\begin{array}{l}\text { A temática alimentação saudável deve ser trabalhada na educação integral, } \\
\text { no turno inverso, em oficinas específicas. }\end{array}$ & & & & & \\
\hline
\end{tabular}




\begin{tabular}{|c|c|c|c|c|c|c|}
\hline \multicolumn{7}{|c|}{ Questionário para investigar as crenças sobre o ensino da temática alimentação saudável no ambiente escolar } \\
\hline $\mathrm{N}$ & Afirmações & $\mathrm{CT}$ & $\mathrm{CP}$ & NCND & $\mathrm{DP}$ & DT \\
\hline 27 & $\begin{array}{l}\text { Em função dos hábitos alimentares serem formados nos anos iniciais da } \\
\text { infância, os professores da Educação Infantil são os mais indicados para } \\
\text { trabalhar a temática alimentação saudável. }\end{array}$ & & & & & \\
\hline 28 & $\begin{array}{l}\text { Os professores deveriam ter acesso a um livro ou manual sobre alimentação, } \\
\text { contendo sugestões de atividades para trabalhar o conteúdo em sala de } \\
\text { aula. }\end{array}$ & & & & & \\
\hline 29 & O livro didático é uma boa fonte de consulta sobre a temática alimentação. & & & & & \\
\hline 30 & $\begin{array}{l}\text { A temática alimentação saudável deveria ser trabalhada pelo professor } \\
\text { com o auxílio técnico do nutricionista. }\end{array}$ & & & & & \\
\hline 31 & $\begin{array}{l}\text { É recomendável que o Ministério da Educação defina, para cada área do } \\
\text { conhecimento ou disciplina, o conteúdo sobre alimentação a ser abordado } \\
\text { pelo professor. }\end{array}$ & & & & & \\
\hline 32 & $\begin{array}{l}\text { Como as Diretrizes Curriculares Nacionais reúnem princípios, } \\
\text { fundamentos e procedimentos que orientam as propostas curriculares } \\
\text { das escolas, deveria ser criada uma diretriz específica para a Educação } \\
\text { Alimentar e Nutricional. }\end{array}$ & & & & & \\
\hline 33 & $\begin{array}{l}\text { Os professores, das diferentes disciplinas e níveis de ensino, estão } \\
\text { preparados para trabalhar a temática alimentação saudável como tema } \\
\text { transversal. }\end{array}$ & & & & & \\
\hline 34 & $\begin{array}{l}\text { O professor não tem conhecimentos suficientes sobre alimentação e } \\
\text { nutrição para trabalhar, como tema transversal, a temática alimentação } \\
\text { saudável. }\end{array}$ & & & & & \\
\hline 35 & $\begin{array}{l}\text { Em função do excesso de informações disponíveis, atualmente, para a } \\
\text { maioria dos professores não é claro o que significa o conceito 'alimentação } \\
\text { saudável'. }\end{array}$ & & & & & \\
\hline 36 & $\begin{array}{l}\text { Os professores se baseiam em seus próprios conhecimentos sobre } \\
\text { alimentação para ensinar sobre a temática. }\end{array}$ & & & & & \\
\hline 37 & $\begin{array}{l}\text { As atitudes do professor com relação à alimentação, no ambiente escolar, } \\
\text { influenciam na alimentação dos seus alunos. }\end{array}$ & & & & & \\
\hline 38 & $\begin{array}{l}\text { Deveria existir no currículo dos cursos de licenciaturas, das diferentes } \\
\text { áreas, uma disciplina que abordasse e discutisse o conceito 'alimentação } \\
\text { saudável'. }\end{array}$ & & & & & \\
\hline 39 & $\begin{array}{l}\text { Há necessidade da oferta de cursos de especialização para professores } \\
\text { sobre o tema alimentação saudável. }\end{array}$ & & & & & \\
\hline 40 & Os professores devem consumir na escola somente alimentos saudáveis. & & & & & \\
\hline 41 & $\begin{array}{l}\text { Os professores são os profissionais mais indicados para trabalhar o tema } \\
\text { alimentação com crianças e adolescentes. }\end{array}$ & & & & & \\
\hline 42 & $\begin{array}{l}\text { Os professores não se acham aptos para assumir o papel de educadores } \\
\text { no campo da alimentação quando julgam que seus hábitos alimentares } \\
\text { são incorretos }\end{array}$ & & & & & \\
\hline 43 & $\begin{array}{l}\text { Muitas crianças vão para a escola para comer, sendo a alimentação escolar } \\
\text { a principal refeição do dia. }\end{array}$ & & & & & \\
\hline 44 & $\begin{array}{l}\text { Os professores se baseiam em suas experiências com alimentação para } \\
\text { ensinar sobre a temática. }\end{array}$ & & & & & \\
\hline 45 & $\begin{array}{l}\text { A alimentação fornecida nas escolas públicas tem como um de seus } \\
\text { objetivos auxiliar a formação de hábitos alimentares saudáveis. }\end{array}$ & & & & & \\
\hline 46 & $\begin{array}{l}\text { O tipo de alimento ofertado na escola, seja na alimentação escolar pública } \\
\text { e/ou no bar/cantina/lanchonete, influencia os hábitos alimentares dos } \\
\text { escolares. }\end{array}$ & & & & & \\
\hline
\end{tabular}




\begin{tabular}{|c|c|c|c|c|c|c|}
\hline \multicolumn{7}{|c|}{ Questionário para investigar as crenças sobre o ensino da temática alimentação saudável no ambiente escolar } \\
\hline $\mathrm{N}$ & Afirmações & $\mathrm{CT}$ & $\mathrm{CP}$ & NCND & DP & DT \\
\hline 47 & $\begin{array}{l}\text { Abordar o tema transversal 'Educação Alimentar e Nutricional' consiste } \\
\text { em trabalhar com os escolares o conteúdo alimentação saudável, em sala } \\
\text { de aula. }\end{array}$ & & & & & \\
\hline 48 & $\begin{array}{l}\text { A 'pirâmide alimentar' é uma estratégia que pode ser utilizada para } \\
\text { trabalhar a temática alimentação saudável em todas as modalidades da } \\
\text { educação básica. }\end{array}$ & & & & & \\
\hline 49 & $\begin{array}{l}\text { Para modificar o hábito alimentar de uma pessoa, basta que ela aprenda } \\
\text { sobre os nutrientes que cada alimento contém. }\end{array}$ & & & & & \\
\hline 50 & $\begin{array}{l}\text { A alimentação da criança é reflexo da alimentação dos adultos com quem } \\
\text { ela convive. }\end{array}$ & & & & & \\
\hline 51 & $\begin{array}{l}\text { O ensino da alimentação saudável tem como objetivos construir a noção } \\
\text { de alimentação saudável, favorecer a autonomia alimentar e melhorar a } \\
\text { alimentação dos escolares. }\end{array}$ & & & & & \\
\hline 52 & $\begin{array}{l}\text { O ensino da alimentação saudável não ocorre somente dentro da sala de } \\
\text { aula. }\end{array}$ & & & & & \\
\hline 53 & $\begin{array}{l}\text { Ações pontuais na escola, como as palestras, não são suficientes para } \\
\text { melhorar a alimentação dos escolares. }\end{array}$ & & & & & \\
\hline 54 & $\begin{array}{l}\text { O ensino da alimentação saudável deve favorecer o consumo de alimentos } \\
\text { naturais e desaconselhar o consumo de industrializados. }\end{array}$ & & & & & \\
\hline
\end{tabular}

Legenda: CT: Concordo Totalmente. CP: Concordo Parcialmente. NCND: Nem Concordo/ Nem Discordo. DP: Discordo Parcialmente. DT: Discordo Totalmente.

O questionário poderá ser aplicado com diferentes envolvidos da comunidade escolar, professores, diretores, coordenadores pedagógicos, manipuladores de alimentos, nutricionistas que atuam na alimentação escolar, tanto na rede pública como privada de ensino. Além disso, para a aplicação do instrumento, pode se optar por uma versão impressa, na qual cada participante receberá uma cópia para preenchimento, ou por uma versão online, na qual o link do documento pode ser encaminhado por meio de correio eletrônico.

Sugere-se que, além das afirmações, na parte inicial do questionário sejam investigadas algumas informações, coletados dados, para traçar o perfil dos participantes/respondentes. Portanto, uma vez que esse questionário poderá ser utilizado para diferentes públicos alvos, como professores, coordenadores pedagógicos e nutricionistas, aconselha-se que a "caracterização do participante" seja adequada ao perfil dos respondentes. Algumas informações: sexo; idade; escolaridade; atuação na educação básica ou na alimentação escolar.

\section{Análise dos dados}

Para avaliar os resultados encontrados na aplicação do questionário, sugere-se, primeiramente, tabular os dados coletados em uma planilha Excel ${ }^{\circledR}$ e, em seguida, 
realizar dois procedimentos, que serão detalhados na sequência: identificação do Escore de cada afirmativa e agrupamento das afirmativas em eixo, de acordo com o conteúdo.

\section{Escore}

Optou-se por empregar, como estratégia para análise dos resultados, o procedimento realizado por Vian (2015) em seu trabalho, baseado em Tastle e Wierman (2007), uma vez que este possibilita identificar para cada afirmativa proposta, por meio de um escore, a direção das respostas de todos os entrevistados para a concordância ou a discordância com cada proposição feita.

Para tanto, primeiramente, para cada uma das alternativas (opções) de resposta, determina-se um peso $(\mathrm{P})$ diferente, sendo, respectivamente, para discordo totalmente (DT), discordo parcialmente (DP), não concordo nem discordo (NCND), concordo parcialmente $(\mathrm{CP})$ e concordo totalmente $(\mathrm{CT})$, os valores 1, 2, 3, 4 e 5 .

Em seguida, a fim de identificar o escore para cada assertiva, aplica-se a fórmula a seguir: Escore $=\left[\left(\mathrm{n}^{\circ} \mathrm{DT} / \mathrm{n}^{\circ}\right.\right.$ total $\left.\left.) \times 1\right)\right]+\left[\left(\mathrm{n}^{\circ} \mathrm{DP} / \mathrm{n}^{\circ}\right.\right.$ total $\left.\left.) \times 2\right)\right]+\left[\left(\mathrm{n}^{\circ} \mathrm{NCND} / \mathrm{n}^{\circ}\right.\right.$ total $)$ x 3$)]+\left[\left(n^{\circ} \mathrm{CP} / \mathrm{n}^{\circ}\right.\right.$ total $\left.\left.) \times 4\right)\right]+\left[\left(\mathrm{n}^{\circ} \mathrm{CT} / \mathrm{n}^{\circ}\right.\right.$ total $\left.\left.) \times 5\right)\right]$. Portanto, o escore final de cada afirmação é obtido a partir do somatório do escore de cada uma das cinco opções de resposta (DT-DP-NCND-CP-CT), que é alcançado pelo percentual de respostas ( ${ }^{\circ}$ respostas da alternativa dividido pelo $\mathrm{n}^{\circ}$ total de resposta) multiplicado pelo peso $(\mathrm{P})$ pré-determinado para a alternativa.

Para exemplificar a aplicação da fórmula para obtenção do escore final, apresentase um caso fictício de respostas para uma determinada afirmação do questionário, respondido por 30 participantes: DT- 1 ; DP- 0 ; NCND- 3; CP- 14; CT- 12. Escore = $[(1 / 30) \times 1]+[(0 / 30) \times 2]+[(3 / 30) \times 3]+[(14 / 30) \times 4]+[(12 / 30) \times 5]$. Portanto, o escore da afirmativa é 4,2 .

Cabe referir que, quando um participante não responde, ou seja, deixa em branco a resposta da afirmativa, para o cálculo do Escore, deve-se considerar somente o quantitativo total de participantes que assinalaram uma das cinco alternativas relacionadas ao grau de concordância. Isso poderá ocorrer na versão impressa do questionário, mesmo sinalizando as afirmativas pares com fundo cinza, para diferenciar das ímpares. Essa estratégia facilita o preenchimento, mas não impede que haja participantes que não respondam algumas afirmações.

Para a interpretação dos resultados encontrados no escore (E), considera-se que uma afirmativa apresenta um escore "alto" quando o valor é maior ou igual a quatro, dado que indica evidências de concordância parcial ou total, enquanto um escore "baixo", com valor menor ou igual a três, representa discordância total ou parcial com a afirmativa proposta. Portanto, quanto mais o valor do escore se aproximar de cinco, maior será a tendência dos participantes concordarem totalmente com a afirmação, e, 
consequentemente, quanto mais próximo o valor for de um, torna-se mais provável que os participantes discordem totalmente da proposição feita.

Cabe salientar que, em função do conteúdo da afirmativa, não se espera que todas apresentem escore "alto". Sendo assim, nem sempre um escore "baixo" é considerado um mal resultado.

\section{Eixos (categorias)}

Outra estratégia a ser utilizada na análise dos resultados é o agrupamento das afirmativas. Para cada eixo, foram selecionadas afirmativas de acordo com o conteúdo, e, por isso, cabe referir que uma mesma afirmativa pode estar presente em eixos diferentes. A seguir, no Quadro 03, apresenta-se cada um dos eixos estruturados a fim de facilitar a análise do conjunto de assertivas.

Quadro 03. Eixos estruturados conforme o conteúdo das afirmativas

\begin{tabular}{|c|c|c|}
\hline Eixo & Descrição (conteúdo) & Afirmações \\
\hline $\begin{array}{c}\text { Eixo 1 } \\
\text { Alimentação no } \\
\text { ambiente escolar }\end{array}$ & $\begin{array}{l}\text { Neste eixo foram agrupadas as afirmativas que possuíam diferentes } \\
\text { aspectos relacionados à alimentação no ambiente escolar, incluindo as } \\
\text { que abordam o papel da instituição (escola), dos adultos (professores) } \\
\text { e da própria alimentação neste local, tanto na rede pública como } \\
\text { privada. Também foram incluídas assertivas específicas relacionadas ao } \\
\text { fornecimento, ao consumo e à comercialização de alimentos na escola } \\
\text { em bares, cantinas e restaurantes, assim como ao Programa Nacional de } \\
\text { Alimentação Escolar (PNAE). }\end{array}$ & $\begin{array}{l}\text { A1; A2; A3; A4; A5; } \\
\text { A6; A7; A8; A37; } \\
\text { A40; A43; A45; A46; } \\
\text { A50 }\end{array}$ \\
\hline $\begin{array}{c}\text { Eixo } 2 \\
\text { Escolares }\end{array}$ & $\begin{array}{l}\text { Este eixo apresenta afirmações cujo conteúdo é específico sobre a } \\
\text { alimentação dos escolares e as suas atitudes com relação à alimentação. }\end{array}$ & $\begin{array}{l}\text { A8; A9; A10; A11; } \\
\text { A12; A13; A43 }\end{array}$ \\
\hline $\begin{array}{l}\text { Eixo } 3 \\
\text { Hábitos e } \\
\text { escolhas } \\
\text { alimentares }\end{array}$ & $\begin{array}{l}\text { Este eixo apresenta afirmações cujo conteúdo refere-se à alimentação } \\
\text { dos escolares, bem como suas escolhas e atitudes frente à alimentação, } \\
\text { apresentando aspectos que poderiam estar envolvidos ou influenciando } \\
\text { os hábitos alimentares. }\end{array}$ & $\begin{array}{l}\text { A1; A8; A11; A12; } \\
\text { A13; A15; A } 17 ; \\
\text { A27; A37; A42; } \\
\text { A45; A46; A49; A50 }\end{array}$ \\
\hline $\begin{array}{c}\text { Eixo } 4 \\
\text { Responsabilidade } \\
\text { pelo ensino } \\
\text { da temática } \\
\text { alimentação } \\
\text { saudável }\end{array}$ & $\begin{array}{l}\text { Este eixo tem como proposta reunir as afirmativas relacionadas com a } \\
\text { "responsabilidade" pelo ensino da temática alimentação saudável no } \\
\text { ambiente escolar. Apresenta afirmações que direcionam a responsabilidade } \\
\text { para os pais, para os professores, para disciplinas específicas como } \\
\text { Ciências Biológicas e Educação Física, para a Educação Infantil, para } \\
\text { uma disciplina ou oficina específica sobre o tema, para o nutricionista, } \\
\text { assim como afirmativas que irão referir a temática como sendo um tema } \\
\text { transversal, a ser trabalhada de forma interdisciplinar e pelo professor } \\
\text { com auxílio técnico do nutricionista. }\end{array}$ & $\begin{array}{l}\text { A2; A14; A18; A19; } \\
\text { A20; A23; A24; } \\
\text { A26; A27; A } 30 ; \text { A41 }\end{array}$ \\
\hline $\begin{array}{c}\text { Eixo } 5 \\
\text { Professores } \\
\text { e o ensino } \\
\text { da temática } \\
\text { alimentação } \\
\text { saudável }\end{array}$ & $\begin{array}{l}\text { Neste eixo há afirmativas relacionadas ao professor e suas atitudes } \\
\text { alimentares, bem como à formação e ao preparo do profissional para } \\
\text { o "ensino" da temática alimentação saudável, assinalando aspectos } \\
\text { relacionados com essa atividade e, também, buscando identificar possíveis } \\
\text { obstáculos e necessidades para efetivá-la. }\end{array}$ & $\begin{array}{l}\text { A16; A28; A30; } \\
\text { A33; A34; A35; } \\
\text { A36; A37; A38; } \\
\text { A39; A40; A41; } \\
\text { A42; A } 44\end{array}$ \\
\hline
\end{tabular}




\begin{tabular}{|c|l|l|}
\hline Eixo & Descrição (conteúdo) & Afirmações \\
\hline & $\begin{array}{l}\text { Neste eixo foram selecionadas afirmativas que apresentam aspectos } \\
\text { relacionados ao "ensino" da alimentação saudável, incluindo possíveis }\end{array}$ & A3; A17; A19; A20; \\
Eixo 6 & objetivos, estratégias e necessidades para efetivá-lo. Além disso, este & A21; A22; A24; \\
Variáveis & eixo reúne as afirmações relacionadas, especificamente, com o ensino da & A25; A28; A29; \\
relacionadas & temática alimentação saudável como sendo um tema transversal, assim & A31; A32; A33; \\
ao ensino da & como afirmações que referem a necessidade de trabalhar o tema em uma & A34; A36; A44; \\
alimentação & disciplina específica ou em oficinas para alunos de turno integral. Além & A47; A48; A49; \\
saudável & disso, apresentam-se afirmações com possíveis obstáculos ou justificativas & A51; A52; A53; A54 \\
& para não efetivar o trabalho de forma transversal e interdisciplinar. & \\
\hline
\end{tabular}

\section{Considerações finais}

O questionário construído neste trabalho consiste em um instrumento para a identificação das crenças relacionadas ao ensino da temática alimentação saudável. Acredita-se que ele pode ser aplicado em diferentes atores envolvidos com a alimentação escolar, permitindo, entre outras possibilidades, constatar a visão tanto de profissionais como de acadêmicos das áreas de educação e nutrição sobre o assunto. Entretanto, por serem consideradas crenças, é importante ter clareza que, possivelmente, na prática, muitas das questões investigadas não sejam efetivamente realizadas ou compatíveis com a realidade dos respondentes.

Após a avaliação do conteúdo das afirmativas, o questionário ficou composto por 54 assertivas que abarcam o ensino da temática alimentação saudável no ambiente escolar, que foram subdivididas em seis eixos: alimentação no ambiente escolar; escolares; hábitos e escolhas alimentares; responsabilidade pelo ensino da temática alimentação saudável; professores e o ensino da temática alimentação saudável; variáveis relacionadas ao ensino da alimentação saudável.

Uma vez que as crenças dos professores sobre o ensino da temática alimentação saudável podem influenciar na proposição de ações didáticas e pedagógicas relacionadas ao tema e, consequentemente, no processo de formação dos hábitos alimentares saudáveis dos escolares, entende-se como necessário verificar as crenças de licenciandos e professores que atuam na Educação Básica, a fim de subsidiar o planejamento de momentos de discussão e reflexão desta temática na formação dos educadores.

Assim como Scoaris, Pereira e Santin Filho (2009, p.906) tinham como propósito desenvolver um instrumento que permitisse, entre outros objetivos, "disponibilizar para a comunidade científica uma ferramenta diagnóstica das ideias prévias de futuros educadores frente à História da Ciência", acredita-se que o questionário elaborado nesta pesquisa poderá ser utilizado como diagnóstico para identificar as crenças de educadores, ou futuros educadores, sobre o ensino da temática alimentação saudável no ambiente escolar, fornecendo subsídios para efetivar a implementação de ações de educação alimentar e nutricional na escola. 
Considera-se que o questionário/instrumento desta pesquisa pode ser utilizado como forma de diagnóstico, parte fundamental para o planejamento de ações de educação alimentar e nutricional, ou, ainda, como uma estratégia para iniciar a discussão sobre o assunto, podendo configurar-se como uma primeira aproximação com o tema. Uma sugestão seria utilizar em um encontro de formação de professores, aplicando primeiramente de forma individual e na sequência propor a discussão em pequenos grupos, com formulação de uma aproximação ou relação entre as afirmações, com a posterior discussão coletiva.

\section{Referências}

ALEXANDRE, N. M. C. e COLUCI, M. Z. O. Validade de conteúdo nos processos de construção e adaptação de instrumentos de medidas. Ciência \& Saúde Coletiva, 16(7):30613068, 2011.

BARBOSA, N. V. S. et al. Alimentação na escola e autonomia - desafios e possibilidades. Ciência \& Saúde Coletiva, Abr 2013, vol.18, no.4, p.937-945.

BEJARANO, N. B. R.; CARVALHO, A. M. P. Tornando-se professor de ciências: crenças e conflitos. Ciência \& Educação, v. 9, n. 1, p. 1-15, 2003.

BOOG, M. C. F. O Professor e a alimentação escolar: ensinando a amar a terra e o que a terra produz. Campinas, SP: Komedi, 2008.

BRASIL. Portaria Interministerial no1010, de 8 de maio de 2006. Diretrizes para a promoção da alimentação saudável nas escolas de educação infantil, fundamental e nível médio das redes públicas e privadas, em âmbito nacional. Diário Oficial da União, Brasília, DF, 09 de maio de 2006.

BRASIL. Ministério da Saúde. Secretaria de Atenção à Saúde. Departamento de Atenção Básica. Manual operacional para profissionais de saúde e educação: promoção da alimentação saudável nas escolas. Brasília: Ministério da Saúde; 2008. 152 p.

BRASIL. Presidência da República. Casa Civil. Lei no 11.947, de 16 de junho de 2009. Dispõe sobre o atendimento da alimentação escolar e do Programa Dinheiro Direto na Escola os alunos da educação básica. Diário Oficial da União, Brasília, DF, 2009.

CFN. Conselho Federal de Nutricionistas. Resolução do CFN n ${ }^{\circ} 380 / 2005$. Dispõe sobre a definição das áreas de atuação do nutricionista e suas atribuições, estabelece parâmetros numéricos de referência, por área de atuação, e dá outras providências.

CFN. Conselho Federal de Nutricionistas. Resolução CFN no 465 de 23 de agosto de 2010. Dispõe sobre as atribuições no Nutricionista, estabelece parâmetros numéricos mínimos de referência no âmbito do Programa de Alimentação Escolar (PAE) e dá outras providências. Diário Oficial da União, 2010

CUSTÓDIO, J. F.; CLEMENT, L.; FERREIRA, G. K. Crenças de professores de física do ensino médio sobre atividades didáticas de resolução de problemas. Revista Electrónica de Enseñanza de las Ciencias, Vol. 11, № 1, 225-252, 2012. 
GALDEANO, L. E.; ROSSI, L. A. Validação de conteúdo diagnóstico: critérios para seleção de expertos. Revista Ciência, Cuidado e Saúde Maringá, v. 5, n. 1, p. 60-66, jan./abr. 2006.

LIKERT, R. A technique for the measurement of attitudes. Archives in Psychology, 140, p. $1-55,1932$.

MELO, R. P. et al. Critérios de seleção de experts para estudos de validação de fenômenos de enfermagem. Rev Rene, Fortaleza, 2011 abr/jun; 12(2):424-31.

MONTEIRO, G.T.R; HORA, H.R.M. Pesquisa em saúde pública: como desenvolver e validar instrumentos de coleta de dados. 1. Ed. Curitiba: Appris, 2014. 112p.

PAIVA, M. L. M. F; DEL PRETTE, Z. A. P. Crenças docentes e implicações para o processo de ensino-aprendizagem. Revista Semestral da Associação Brasileira de Psicologia Escolar e Educacional (ABRAPEE), Volume 13, Número 1, 75-85, Janeiro/Junho de 2009.

RUWER, C. M.; MAINBOURG, E. M. T. Promoção da alimentação saudável em escolas Particulares. Vig Sanit Debate 2015;3(1):67-74.

SCARPARO, A. L. S. Crenças sobre o ensino da temática alimentação saudável no ambiente escolar. Tese (Doutorado em Educação em Ciências). Universidade Federal do Rio Grande do Sul, Programa de Pós-Graduação Educação em Ciências: Química da Vida e Saúde. Porto Alegre, junho de 2017.

SCOARIS, R. C. O.; PEREIRA, A. M. T. B.; SANTIN FILHO, O. Elaboração e validação de um instrumento de avaliação de atitudes frente ao uso de história da ciência no ensino de ciências. Revista Electrónica de Enseñanza de las Ciencias, Vol.8, No3, 2009.

SILVA JUNIOR, S. D.; COSTA, F. J. Mensuração e Escalas de Verificação: uma Análise Comparativa das Escalas de Likert e Phrase Completion. Revista Brasileira de Pesquisas de Marketing, Opinião e Mídia, São Paulo, Brasil, V. 15, p. 1-16, outubro, 2014.

SOARES, I. M. F.; BEJARANO, N. R. R. Crenças dos professores e formação docente. R. Faced, Salvador, n.14, p.55-71, jul./dez. 2008.

VIAN, V. Ensino médio politécnico: relação entre a pesquisa e o professor pesquisador. Dissertação (Mestrado em Ensino). Centro Universitário UNIVATES, Programa de PósGraduação em Ensino. Lajeado, junho de 2015. 